\title{
Percepção ambiental e narrativas visuais da transformação da paisagem e suas relações com o turismo na Ilha Comprida (SP)
}

\author{
Environmental perception and visual narrative of \\ transformation of landscape and their relations with the \\ tourism in Ilha Comprida (SP, Brazil)
}

\author{
Izaias Carmacio Junior, Diogo Fernando Rodrigues, \\ Luiz Afonso Vaz de Figueiredo
}

\begin{abstract}
RESUMO
O município de Ilha Comprida está localizado na região do baixo Vale do Ribeira e Litoral Sul do estado de São Paulo, sendo emancipado politicamente em 1992. Possui vegetação nativa de Mata Atlântica, associada com manguezais, restingas e dunas, além de extensa faixa litorânea, incluído em 1987 em uma Área de Proteção Ambiental (APA). A localidade está sujeita às atividades de turismo e segunda residência, sofrendo problemas socioambientais com o processo de urbanização e construção da ponte de interligação com o continente. O presente artigo tem por objetivo analisar a percepção ambiental e os processos de transformação da paisagem, vivenciados por moradores locais, tendo como estudo de caso o trecho entre o Bairro Boqueirão e a Ponta da Praia na parte norte de Ilha Comprida. Os dados foram coletados por meio de depoimentos orais com 10 moradores que tinham mais de 10 anos de residência ou contato com a llha, identificando as relações homem-natureza e modificações do meio físico. Para a composição das narrativas visuais foram escaneadas fotografias antigas do município obtidas com os entrevistados e realizado um levantamento fotogeográfico nos anos de 20122013, além de imagens coletadas em meio eletrônico ou disponibilizadas pela Prefeitura Municipal da Ilha Comprida. Observou-se que os moradores perceberam forte processo de transformação da paisagem, com destaque para a influência após a construção da ponte em 2001. As imagens antigas quando comparadas com as fotos recentes demonstraram as modificações da paisagem principalmente no que se refere à construção civil, impermeabilização do solo, presença de resíduos sólidos, avanço do mar destruindo habitações e introdução de espécies vegetais exóticas. Ressaltase a necessidade de se provocar discussões e subsidiar ações de educação ambiental e ecoturismo, visando a melhoria da qualidade de vida nessa região do complexo estuarino-lagunar paulista.
\end{abstract}

KEYWORDS: Percepção Ambiental; Narrativas Visuais; Transformação da Paisagem; Ilha Comprida (SP). 


\section{ABSTRACT}

The municipality of Ilha Comprida is located at the region of Vale do Ribeira and South coast of the state of São Paulo, it has been politically emancipated in 1992. There is Atlantic Forest vegetation related to mangroves, sandbank and dunes, besides the stretch of coast, incluted in 1987 in a Environmental Protected Area (EPA). The location is associated with touristic activities and second residences, the region suffers environmental problems related to the process of urbanization and the construction of the bridge with the continent. The goal of this article is to analyze the environmental perception and the process of landscape transformation, felt by the residents located on the stretch between Boqueirão and Ponta da Praia neighborhood on the North part of Ilha Comprida. The datas were collected by oral testimonies with 10 residents who lived over 10 years or are associated with island, it was possible to identify the relationship human-nature and the modifications of the physical environment. It was possible to make the composition of the visual narratives thanks to antique photographs obtained with the residents, and accomplished a photogeographic survey produced between 2012 and 2013, besides the images collected from the city hall of Ilha Comprida. The results demonstrated that the residents noticed a strong process of landscape transformation, they highlighted a great influence after the building of the bridge in 2001. The antique images compared to the current photographs demonstrated that the mainly modifications on the landscape was related to the asphalt, increasing numbers of residences, soil sealing, huge presence of solid waste, advance of sea level and destroyed houses, introduction of exotic species and destruction of local vegetation along the coastline. The study emphasized the necessity to induce and subsidize actions of environmental education and ecotourism, in order to improve the quality of life on the region of the lagoon-estuarine complex in São Paulo.

KEYWORDS: Environmental Perception; Visual Narratives; Landscape Transformation; llha Comprida (SP).

\section{Introdução e justificativa}

O município de Ilha Comprida está localizado na região do baixo Vale do Ribeira e Litoral Sul do estado de São Paulo, sendo emancipado politicamente em 1992. Possui vegetação nativa de Mata Atlântica, associada com manguezais, restingas e dunas, além de extensa faixa litorânea, incluído em 1987 em uma Área de Proteção Ambiental (APA), caracterizada regionalmente no Complexo Estuarino-Lagunar de Iguape-Cananéia-Ilha Comprida. (COSTA-PINTO; SORRENTINO, 2002; BEU, 2008).

Com a conclusão da ponte Laércio Ribeiro em 2001, o acesso à Ilha Comprida foi facilitado, de um lado aumentando as atividades econômicas associadas ao turismo, por outro lado, esse processo vem ocasionando transformações na paisagem em um período de menos de 20 anos.

O modo tradicional de turismo em São Paulo se baseia no modelo sol e praia, consequentemente, a Baixada Santista tornou-se um local de muita procura durante o período de férias por ser de mais fácil acesso da metrópole paulista, no entanto, não tem suportado o grande número de frequentadores. Sendo assim, novas alternativas de lazer foram procuradas, como as praias do litoral sul, onde se localiza Ilha Comprida.

A questão relativa à forma como ocorre o turismo é fundamental para o entendimento dos processos de transformação da paisagem, 
principalmente nesses municípios em que a atividade turística ganha um status de principal atividade econômica. Por outro, Domiciano e Oliveira (2012, p.180), ponderam que:

O turismo muito além de ser uma atividade- econômica apresenta-se como um processo de produção social que interfere em vários setores da sociedade, como o setor econômico, o social, o cultural e o ambiental.

O objetivo da pesquisa foi identificar e analisar os processos de transformação da paisagem da Ilha Comprida (SP) por meio de depoimentos orais, narrativas visuais e levantamento fotogeográfico, avaliando a influência do turismo e a ocupação humana em relação à transformação da paisagem, tais como a presença de resíduos sólidos, a supressão e alteração da vegetação nativa e contaminação do lençol freático e cursos d'água.

\section{Referencial conceitual}

\section{Percepção Ambiental}

A percepção ambiental de cada indivíduo está relacionada com suas funções sensoriais, destacando-se a visão e podendo ser limitada por laços afetivos vivenciados com sua cultura. Segundo Tuan (1980):

Um ser humano percebe o mundo simultaneamente através de todos os seus sentidos. A informação potencialmente disponível é imensa. No entanto, no dia a dia do homem, é utilizado somente uma pequena porção do seu poder inato para experienciar (TUAN, 1980, p. 12).

Os estudos de percepção ambiental são adequados para entender a relação que ocorre entre pessoas que tenham contato duradouro com uma região, a partir da ligação topofílica que ocorre com a paisagem.

Topofilia estaria relacionada com o sentimento, a relação de alegria e laços afetivos que o ser humano tem com o seu ambiente (TUAN, 1980, p. 129). O autor pondera, entretanto, dizendo que "O meio ambiente pode não ser a causa direta da topofilia, mas fornece o estímulo sensorial que, ao agir como imagem percebida, dá forma às nossas alegrias e ideais" (TUAN, 1980, p. 12).

A percepção ambiental permite a busca de informações essenciais, baseadas na memória, que podem ser descritas e hierarquizadas. Conforme sugerido por Amorim Filho (1992), os estudos podem focar os seguintes temas.

qualidade ambiental; paisagens valorizadas; riscos ambientais; representações do mundo; imagens de lugares distantes; história das paisagens; relações entre as artes, as paisagens e os lugares; espaços pessoais; construção de mapas mentais; percepção ambiental e planejamento. (AMORIM FILHO, 1992). 


\title{
Narrativas visuais
}

As narrativas visuais demonstram o sentimento estimulado ao descrever uma imagem, determinando diversas interpretações epistemológicas, destacando aspectos históricos, expressões faciais e transformações do ambiente ou algo pessoal em um determinado período de tempo ou ainda em longo prazo.

Nobre (2011, p.114) em seu trabalho de fundamentação sobre o papel das imagens como narrativas visuais destaca que "ao concebermos a imagem como narrativa visual, admitimos que o cenário retratado é determinante do universo sociocultural analisado". O autor discorda do uso da fotografia como material secundário, complementar ou meramente ilustrativo, posto como mera oposição à linguagem literária. A imagem ganhou destaque como forma de narrativa que antes era exclusividade da palavra. (NOBRE, 2009, 2011).

De acordo com Nobre (2011) a riqueza do uso da narrativa visual não está relacionada com a qualidade da imagem, mas com a cultura ou vivência de quem as interpreta. As imagens ajudam a compor interpretações da realidade analisada.

\begin{abstract}
A fotografia pode ultrapassar esses limites e permitir ao imaginário transpor códigos lineares, penetrar a polissemia da narrativa visual, sendo um signo cuja indicialidade representa, de forma mais próxima, as particularidades do seu referente. Através da fotografia, podemos perceber a singularidade de uma representação que indica informações referentes ao meio sociocultural onde foi concebida. [...] Assim, a imagem fotográfica pode ser relida e revivida, trazida de volta à lembrança para estimular a memória (NOBRE, 2011, p. 114).
\end{abstract}

O trabalho de referência sobre uso de narrativas visuais para compreender a paisagem do ponto de vista sociocultural foi desenvolvido por Nobre $(2003,2005)$, fundamentando e aplicando a metodologia no interior do Rio Grande do Norte.

Alguns estudos têm sido realizados aplicando as narrativas visuais como caminho para identificar a percepção ambiental e representações de meio ambiente, muitas vezes, também, vêm associadas a depoimentos orais, ou mesmo traçando contraposições com outras diversas imagens de épocas diferentes, propiciando reflexões sobre a transformação da paisagem.

Araújo (2006) utiliza imagens e depoimentos para compor um mapeamento da transformação da paisagem em áreas urbanas da região metropolitana de São Paulo.

Outro autor que utiliza a metodologia e realiza uma discussão do potencial das narrativas visuais é Figueiredo (2010), que em seu trabalho de doutorado buscou entender as cavernas como paisagens racionais e 
simbólicas, para isso as imagens foram fundamentais para a construção do discurso investigado.

O uso das imagens fotográficas no contexto de análise para a produção do discurso das atividades espeleológicas e do turismo em cavernas, com destaque para Alto Ribeira, foi fundamental para compreender a dinâmica do fenômeno, assim como para avaliarmos de que modo as fotografias poderiam demonstrar o potencial investigativo das narrativas visuais (FIGUEIREDO, 2010, p. 98).

\section{Procedimentos metodológicos}

\section{Área de Estudo}

Ilha Comprida está localizada na Planície Litorânea, na região sul do litoral paulista, sendo uma longa e estreita restinga da Região EstuarinoLagunar Cananéia/Iguape/Paranaguá, conhecida como Lagamar. Está situada a poucos metros de altura acima do nível do mar, possuindo cerca de $70 \mathrm{~km}$ de comprimento por $3 \mathrm{~km}$ de largura (Figura 1).

A região está localizada a $200 \mathrm{~km}$ da cidade de São Paulo e $260 \mathrm{~km}$ de Curitiba, que são dois grandes centros emissores turísticos. A Ilha Comprida possui uma área total de $189 \mathrm{~km}^{2}$ e uma população estimada em 10.102 habitantes, de acordo com o Censo IBGE de 2014.

A limitação da área de estudo foi da região do Boqueirão até a Ponta da Praia, localizado no lado norte da llha (Figura 1). Essa escolha foi determinada devido à facilidade de acesso ressaltando a área mais sujeita a processo de urbanização e degradação do meio ambiente.

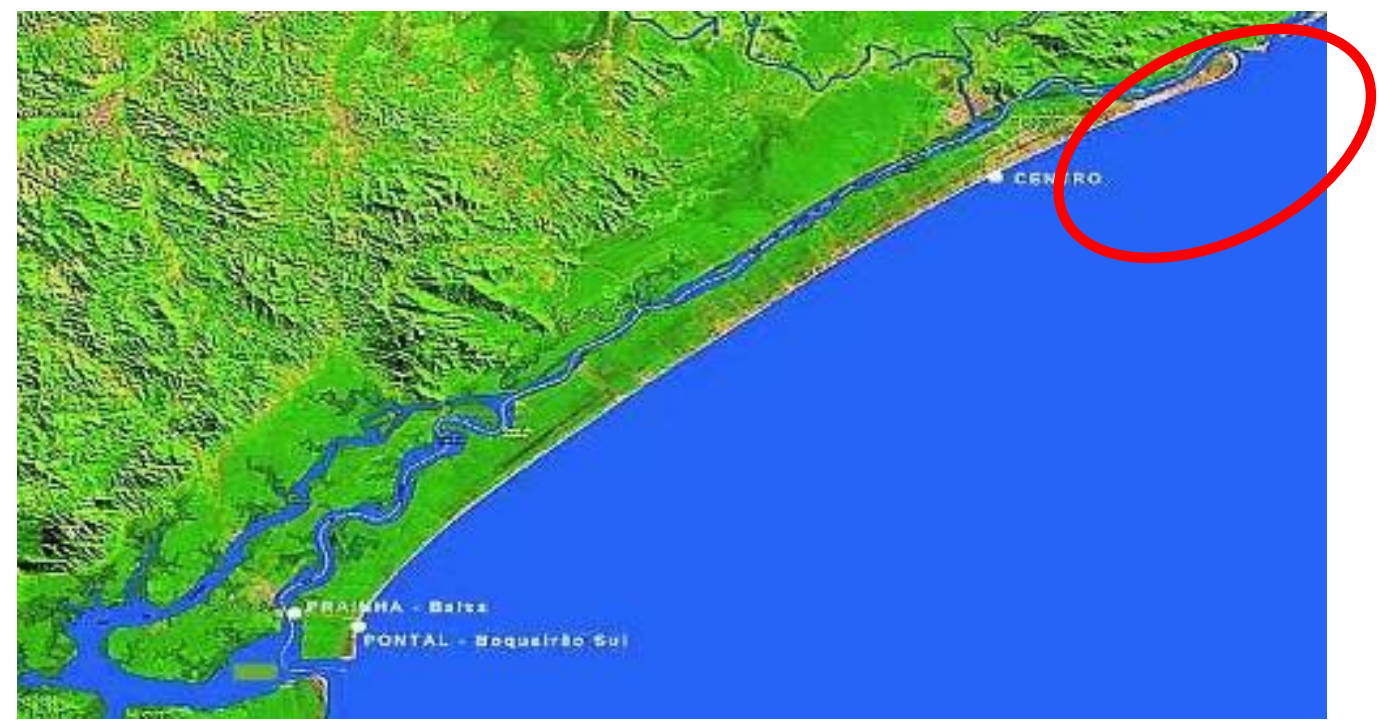

Figura 1: Mapa da llha Comprida e região do entorno e destaque em vermelho para a área de estudo. Centro e Boqueirão norte. Fonte: http://www.llhabela.net/praias/ilhacomprida.htm.

Figure 1: Map of Long Island and the surrounding region and highlighted in red for the study area. Central and northern Boqueirão.

Source: http://www.ilhabela.net/praias/ilhacomprida.htm. 


\section{Trabalho de Campo}

A execução da pesquisa ocorreu entre 2012 e 2013. Durante as visitas de campo foram feitas observações gerais da situação da área de estudo, foi também o momento em que se conseguiu contato com os moradores locais, com os quais foram coletadas informações, documentos e fotos que caracterizaram os processos vivenciados de transformação da paisagem na área de estudo.

O reconhecimento geral preliminar foi realizado em julho de 2012, quando ocorreu o primeiro levantamento fotográfico e contatos com moradores. Na etapa de coleta de dados optou-se por realizar o trabalho em dois momentos distintos, janeiro de 2013, momento de alta temporada e julho de 2013, época de baixa temporada, período esse que se mostrou mais adequado para realizar os depoimentos orais, pois os entrevistados mostraram mais disponibilidade e tranquilidade, principalmente na Prefeitura, quando os funcionários puderam dar maior atenção às entrevistas.

\section{Depoimentos orais}

Os estudos de percepção ambiental e transformação da paisagem foram realizados na llha Comprida (SP), com pessoas que moram ou tenham contato duradouro na região entre o Bairro do Boqueirão (norte) e a Ponta da Praia. Para isso, foram selecionados moradores que tinham contato com a região por mais de 10 anos e que trafegavam pela antiga balsa do município antes da conclusão da ponte Laércio Ribeiro em 2001, testemunhando o desenvolvimento turístico influenciado pela obra que interliga o município de Iguape à llha Comprida.

As entrevistas foram realizadas por meio de depoimentos orais gravados em I-Phone Apple (Modelo 4S) e posteriormente transcritos em editor de texto Word.

Os depoimentos permitiram analisar a diferenciação da percepção que cada um possuía, tendo em vista que duas pessoas não iram assimilar a realidade da mesma maneira ou mesmo grupos sociais diferentes não fazem exatamente a mesma avaliação do meio ambiente, tal como descrito por Tuan (1980, p.6).

Foram entrevistadas 10 pessoas, conforme possibilidades e disponibilidades. Não houve um tempo estimado à priori, uma vez que cada entrevistado teve a oportunidade de se expressar livremente com o tempo necessário, de acordo com cada temática solicitada. O tempo médio das entrevistas foi de 11 minutos.

As entrevistas foram feitas utilizando um roteiro semiestruturado, visando coletar dados sobre os seguintes aspectos: Dados pessoais, relação com a llha Comprida e tempo de contato; aspectos históricos da llha; percepção para a transformação da paisagem; sensações e sentimentos em relação à llha; além de fotos históricas da região. 


\section{Levantamento fotográfico e composição de narrativas visuais}

As fotos foram produzidas utilizando câmera fotográfica digital Nikon D5000 e Apple Iphone 4S, durante o ano de 2012 e 2013. Esse material imagético foi digitalizado de modo a compor um corpus fotográfico, complementado pelas fotos feitas em outras épocas pelos responsáveis da pesquisa e outras cedidas pelos entrevistados a respeito dos processos de transformação da paisagem na llha Comprida, sendo posteriormente selecionadas para a compor narrativa visual.

As narrativas visuais foram construídas a partir do levantamento fotográfico que em conjunto com os depoimentos orais, pode compor um visão mais ampla do processo, tal como desenvolvido no estudo realizado por Araújo (2006).

\section{Resultados e discussão}

\section{Percepção ambiental dos moradores da llha Comprida}

Um aspecto muito citado pelos moradores em relação à paisagem foi a preservação na região Sul, por ser um local com maior quantidade de vegetação nativa e devido ao difícil acesso. Segundo a opinião de um entrevistado: "O Boqueirão Sul, para mim é o top porque o Boqueirão Sul representa o que era aqui [Boqueirão Norte] há 20 anos atrás" (D-6, funcionário público, ensino superior). Os relatos reforçam como a paisagem mudou consideravelmente na região do Boqueirão Norte, onde se vê a introdução de plantas exóticas, como pinheiros, eucaliptos e ornamentais.

Durante as entrevistas, houve queixa dos moradores em relação à segurança do município, isso ocorre durante a alta e mesmo na baixa temporada, grande influência está relacionada com a construção da ponte. Segundo um dos entrevistados: "Dependíamos do progresso, ele veio com a ponte, e saindo a ponte acabou a segurança" (D-6, funcionário público, ensino superior) e completa dizendo que "o pessoal entra sem fiscalização e o pessoal sai sem fiscalização", isso mostra a insegurança não só dele, mas de muitos outros moradores, inclusive outros entrevistados que vivenciam esses acontecimentos.

Existe também outro ponto de vista relacionado ao comércio e/ou fator econômico, de acordo com as épocas, ou seja, baixa e alta temporada, durante quatro meses, quando o número de turistas está elevado, o movimento econômico aumenta, porém no decorrer dos oito meses restantes o número de turistas é muito baixo, afetando assim os comerciantes. Segundo constata o entrevistado D-9:

(...) "falta de dinheiro, a parte econômica realmente é complicada, a gente passa aqui durante 4 meses em pé, depois você fica meio derrubado, vejam vocês mesmo, o tempo que estão aqui e ninguém entrou ainda, quer dizer, é praticamente o dia todo, então nós somos uns guerreiros" (D-9, comerciante, ensino médio). 
Tendo em vista a ocupação humana muito próxima da linha litorânea, tais como construções de residências, observou-se em aproximadamente 10 anos que diversas casas foram destruídas pelo mar. De acordo com o entrevistado D-6:

"A Ponta da Praia Norte mudou muito, pois quem observa a Praia do Leste na região de Icapara não imagina que existia um pico com casas e pousadas, que atualmente está inundada pela ação das marés" (D-6, funcionário público, ens. sup.).

O processo de urbanização é também destacado nos depoimentos. Como exemplo temos o entrevistado D-5 (funcionário público, ensino superior): "tem muitas construções aqui, hoje a cada dia a Ilha ganha novas casas, e isso com o passar dos anos vai mudando as características da cidade". Destaca-se aqui uma visão focada no processo de urbanização, em contraposição, o entrevistado D-7 (funcionário público, ensino superior) diz; "a própria Ponta da Praia, uma das coisas que eu gosto é que ela sempre está modificando".

"O desenvolvimento... aqui só tinha areia, não tinha rua, não tinha nada, mas agora tá urbanizada, é uma cidade urbanizada, isso começou depois da emancipação, antes não, porque lguape não fazia nada aqui, por isso que nós emancipamos, para poder desenvolver". (D-8, funcionário público, ensino superior).

\title{
Narrativas visuais da transformação da paisagem
}

\section{O boqueirão}

A atividade turística cresceu depois que a ponte Laércio Ribeiro que interliga o município de lguape com llha comprida passou a funcionar, facilitando 0 acesso ao município. No caso da foto 1, observa-se 0 desenvolvimento na orla com o asfaltamento e, consequentemente, veio a ampliação do comércio e maior concentração de pousadas, sendo mais evidente esta transformação na parte norte em comparação com a região sul da Ilha Comprida. De acordo com a opinião do entrevistado D-2:

\begin{abstract}
"Ah! O progresso tem chegado, tem loteamento ai que não tinha rua aberta, foram abertas as ruas, todas elas foram calçadas. De uns 20 anos pra cá, porque antes só existiam as ruas, depois foi melhorada, reformada, muita obra sendo feita, muita construção" (D-2, comerciante, ensino superior).
\end{abstract}

Essa parte da llha é considerada a área que sofreu maior urbanização, diferente do Boqueirão Sul, que está próxima a Cananéia, onde a paisagem permanece mais preservada com maior incidência de dunas e uma faixa litorânea mais larga, porém é uma área com maior dificuldade de acesso, por isso a concentração de turistas se restringe muitas vezes mais no Boqueirão Norte. 
"E hoje a avenida principal em uns 20 e poucos quilômetros da Avenida Beira Mar asfaltado. Mesmo na relação de esgoto, aqui existem duas estações de tratamento de esgoto" (D-7, funcionário público, ens. sup.).

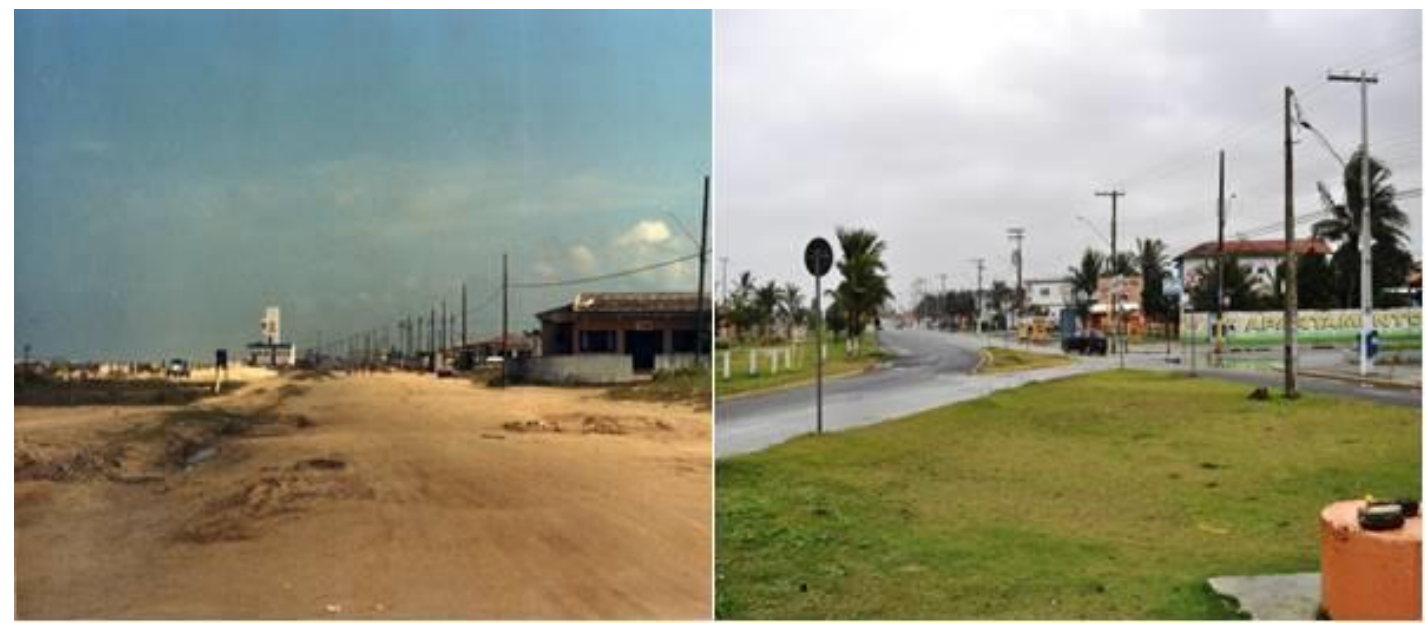

Foto 1: Boqueirão Norte em 1990 (esquerda) e 2013 (direita), vista em direção à Cananeia. Fonte: Luiz Afonso V. Figueiredo (1990); Diogo F. Rodrigues, (2013).

Photo 1: Boqueirao North in 1990 (left) and 2013 (right), seen in the direction of Cananeia . Source: Luiz Afonso V. Figueiredo (1990); Diogo F. Rodrigues, (2013).

\section{O desenvolvimento urbano da llha e a ponte}

A ponte foi implantada em 2001, sendo a principal via de acesso à Ilha Comprida e proporciona facilidade para quem visita e mora, trazendo também o desenvolvimento para o município segundo a percepção dos entrevistados, que enfrentavam problemas como falta de água, esgoto, iluminação e transporte segundo os moradores.

"Depois da saída da ponte, quando tínhamos a balsa aqui. $O$ desenvolvimento estava parado, não tinha progresso com a balsa. Precisávamos que algo acontecesse, porque quem vivia aqui em 1996, como meu caso, aqui era intransitável' (D-6, funcionário público, ens. sup.).

Ao discutir com os moradores sobre a mudança da paisagem na Ilha Comprida, foi apontado o desenvolvimento na questão do saneamento básico. Antes de 2001, o município sofria com problemas de esgoto, acesso á água potável e energia elétrica. Devido ao difícil acesso causado pelo transporte via balsa que resultava em filas enormes de carros para poder atravessar, ou seja, as pessoas muitas vezes necessitavam de um pouco de paciência para conseguir chegar até o outro lado, mas hoje não é mais necessário se preocupar com esse detalhe, já que o acesso é pela ponte (Foto 2), e a balsa ficou apenas na memória.

"Eu trouxe muita gente, mais de 1.000 pessoas pra conhecer a Ilha, pois muita gente comprava terreno e depois eu mostrava a llha, chegava na Ilha, tinha uma balsa para atravessar e a balsa demorava, levava muitas horas, 
8,10,12 horas ou mais para poder chegar aqui, em época de temporada levava até 20 horas para atravessar(...)" ((D-6, corretor de imóveis, ens. sup.).

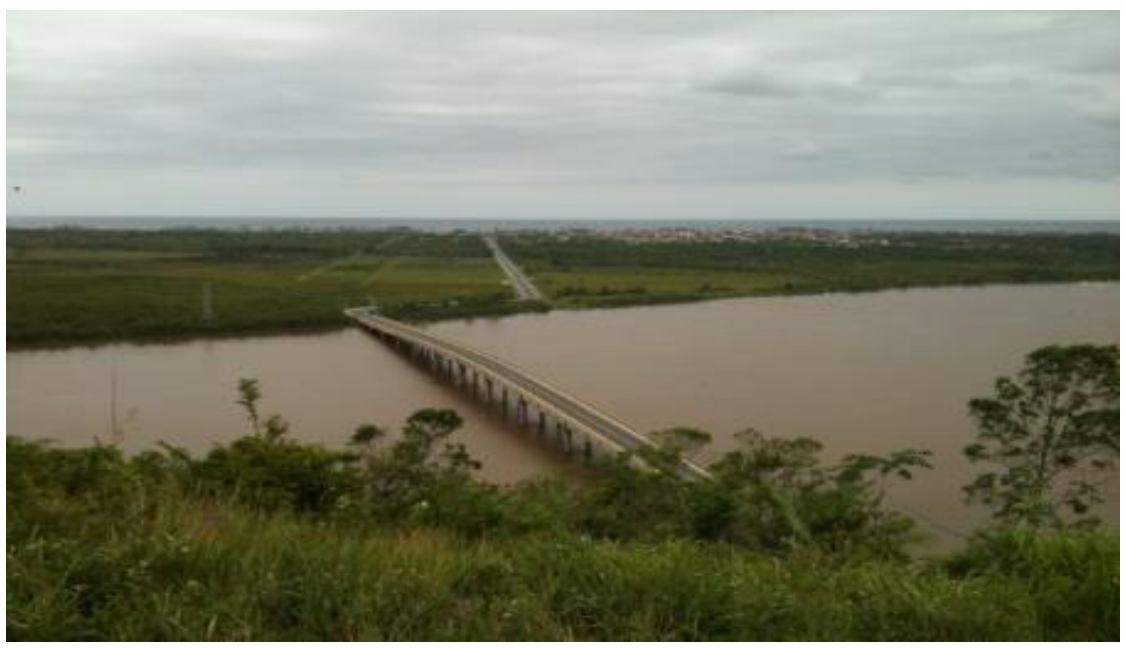

Foto 2: Ponte Laércio Ribeiro, interligação Iguape e llha Comprida. Fonte: Luiz Afonso V. Figueiredo (1990); Diogo F. Rodrigues, (2013).

Photo 2: Laércio Ribeiro Bridge, linking Iguape and Ilha Comprida. Source: Luiz Afonso V. Figueiredo (1990); Diogo F. Rodrigues, (2013).

Depois da implantação da ponte, que além de abrir um novo acesso para novos visitantes, também facilitou o transporte para implantação de serviços básicos para os munícipes. Com o desenvolvimento e crescimento urbano, também houve novos problemas, como a falta de segurança devido ao aumento dos frequentadores, ocasionando um insuficiente abastecimento de água no município e queda frequente de energia.

A falta de fiscalização implicou também no crescimento de lotes irregulares, gerando conflitos fundiários, tendo em vista que toda a Ilha Comprida está inserida em uma Área de Proteção Ambiental (APA).

O processo de desenvolvimento da llha Comprida continua em andamento (Foto 3) e cresce a cada ano, e os moradores podem contar com maiores recursos como o desenvolvimento da orla junto à praia, 0 tratamento de esgoto junto com a expansão do asfalto que esta chegando a outros balneários que antes não tinham.

"Ah, com certeza ta mudando, mudanças em casas, residências, locomoção porque antes não tinha asfalto, ruas, muitos loteamentos existem ainda, então $70 \%$ da llha tem acesso e os outros 30\% está em área verde" (D-3, corretor de imóveis, ensino médio). 


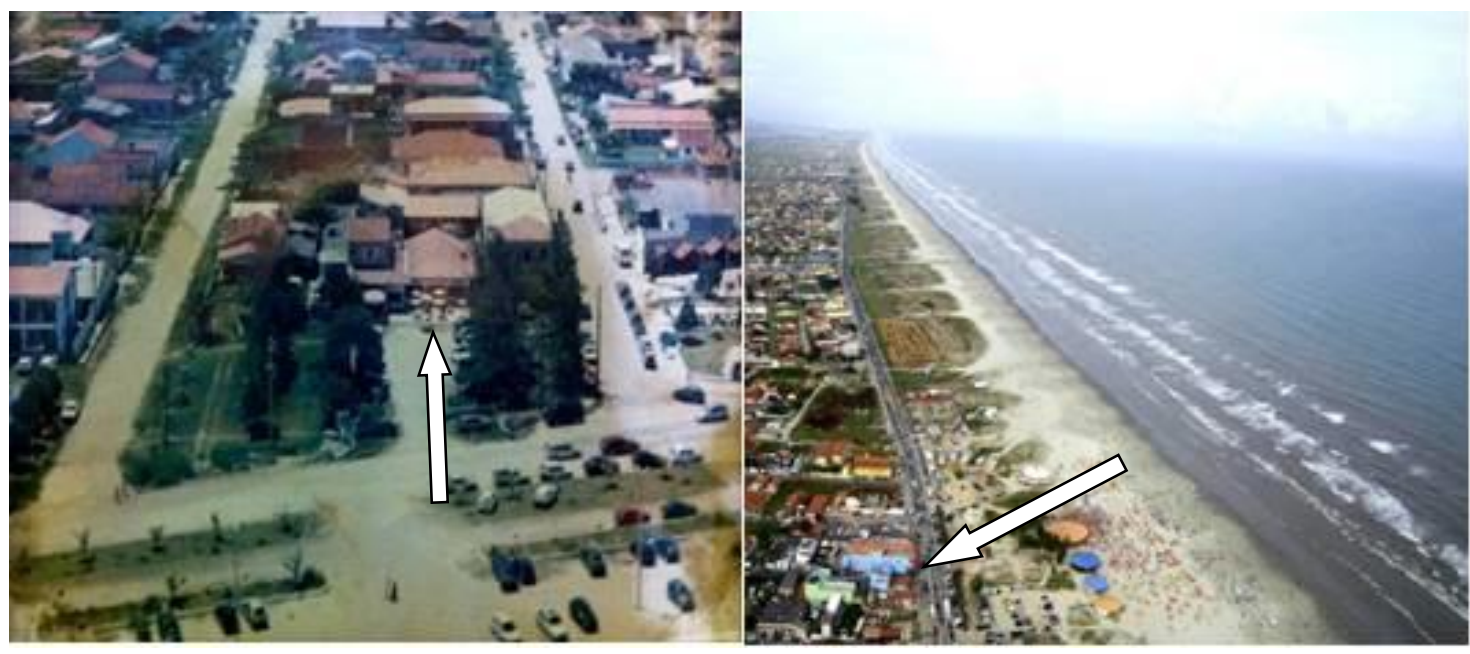

Foto 3: Boqueirão Norte, setas indicam como referência o restaurante Boi da llha em 1981 e 2007 respectivamente. Fonte: Imagens da Prefeitura Municipal da llha Comprida (1981 e 2007).

Photo 3: Boqueirao Norte, arrows indicate reference to the Island Boi Restaurant in 1981 and 2007 respectively. Source: Images of the City of Ilha Comprida (1981 and 2007)

\section{Transformação da paisagem na Ponta da Praia}

No balneário Ponta da Praia é onde o mar recebe muitos sedimentos devido ao Rio Ribeira, por isso a característica da água na região norte é diferente em comparação com a região sul da Ilha, pois o rio traz sedimentos que deixa o mar com uma coloração mais barrenta, consequentemente a água fica turva. De outro lado, um grande problema para os moradores, segundo eles é que "a Ilha está afunilando", ou seja, uma extremidade está sendo engolida pelo mar enquanto a outra está se expandindo, correspondendo norte e sul, respectivamente.

"Pelo lado norte, observei com o passar do tempo tinha algumas casas que o mar avançou e acabou derrubando essas casas, e interessante no lado sul aumentou. Então esse é um fenômeno que acredito que seja natural que vem decorrendo, mas eu também acredito que seja pela influência pela abertura da barragem aqui do Ribeira de Iguape" (D-5, funcionário público, ens. sup.).

O processo de transformação continua a cada ano sendo mais visível devido ao avanço anual do nível do mar, isso foi observado em Janeiro de 2013 a Julho de 2013 pelos pesquisadores, proporcionando uma análise comparativa do local (Fotos 4 e 5). 


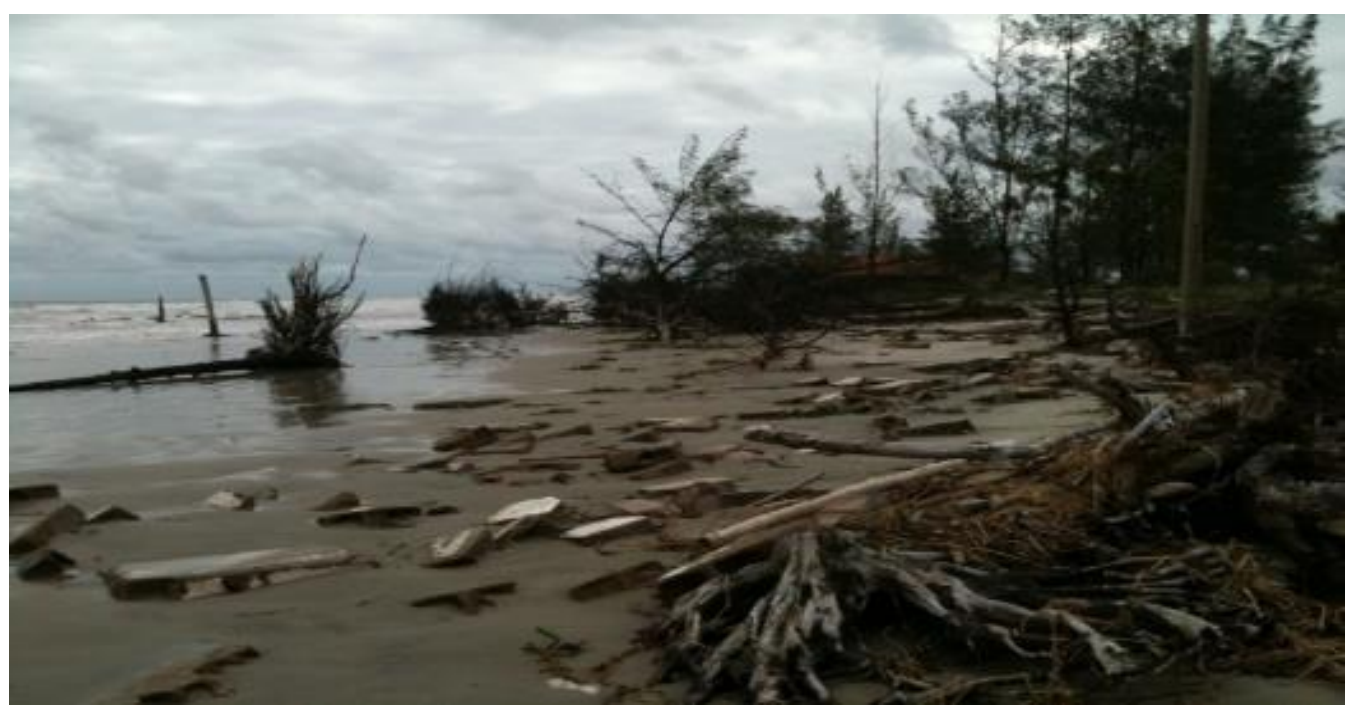

Foto 4: Destruição das residências e exposição de sistema radicular das árvores na Ponta da Praia. Fonte: Diogo F. Rodrigues (2013).

Photo 4: Destruction of homes and root exposure of trees in Ponta da Praia.

Source: Diogo F. Rodrigues (2013).

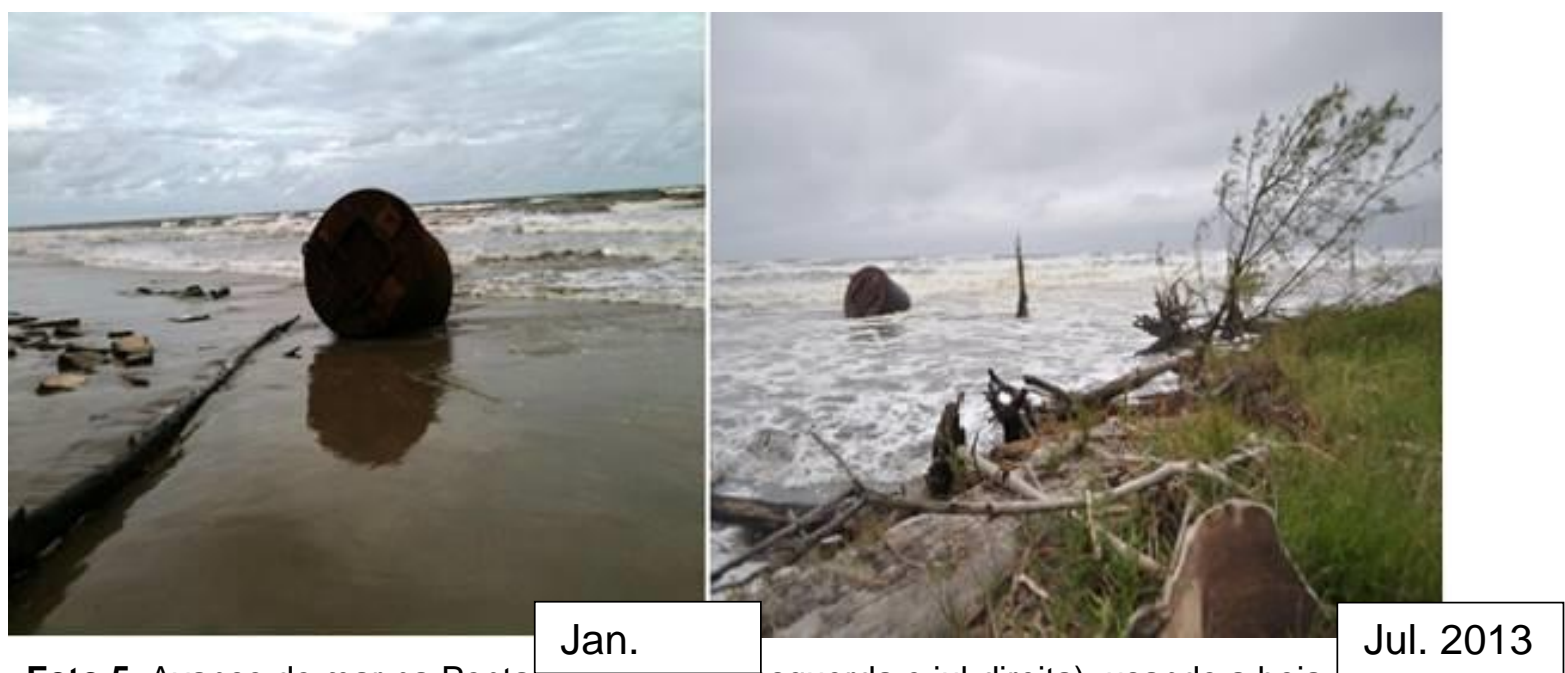

Foto 5: Avanço do mar na Ponta da rrara (jant-esquerda e jul-direita), usando a boia comtro referência. Fonte: Diogo F. Rodrigues (2013).

Photo 5: Sea Advancement in Ponta da Praia (Jan- Jul- left and right), using the float as a reference. Source: Diogo F. Rodrigues (2013).

"A Ponta da Praia Norte mudou muito, pois quem observa a Praia do Leste na região de Icapara não imagina que existia um pico com casas e pousadas, que atualmente está inundada pela ação das marés. Para a gente que navega pra poder entrar no canal da Juréia era obrigado contornar pelo mar e ter acesso ao canal da Juréia, atualmente entrase direto pelo canal do mar pequeno" (D-6, funcionário público, ens. sup.). 


\section{Acúmulo de resíduos sólidos}

Com o número elevado de frequentadores, o município sofre com o grande acúmulo de lixo. Um dos entrevistados (D-6) afirma que isso é decorrente da "falta eficiente na fiscalização", devido ao acesso facilitado. O lixo jogado na praia por visitantes e frequentadores é revelado a partir do fenômeno da ressaca do mar no inverno que é possível ver de forma mais compacta graças a esse processo. Outra fala que pode confirmar essa questão foi citada pelo entrevistado (D-3), "o cara vem aqui, acampa na praia e sabe que não pode, e deixa 300 toneladas de lixo".

"Que me incomoda? Quando o próprio turista ou o morador que fica jogando lixo! Me incomoda demais! E os urubus que pegam o lixo para sobreviver, mas acabam espalhando tudo" (D-10, funcionário público, ensino médio).

A prefeitura desenvolve projetos para tentar controlar o descarte dos resíduos sólidos, como o Cidade Limpa (Foto 6), no entanto, não é isso que se observa na paisagem.

"Depende da educação das pessoas. Olha, recentemente teve um concurso nas escolas do ensino fundamental com frases da cidade na parte de limpeza, e as melhores frases estão espalhadas nas cidades, nos pontos de ônibus e com fotografias da parte bonita da llha, pra chamar a atenção das pessoas pra preservar. Tem sim um trabalho de conscientização, começando pelas crianças. Aí acho que depende muito das pessoas, esse lado de educação ambiental começa no berço, não só nas escolas, dentro de casa, acho que a maioria dos brasileiros não tem essa conscientização" (D-7, funcionário público, ens. sup.).

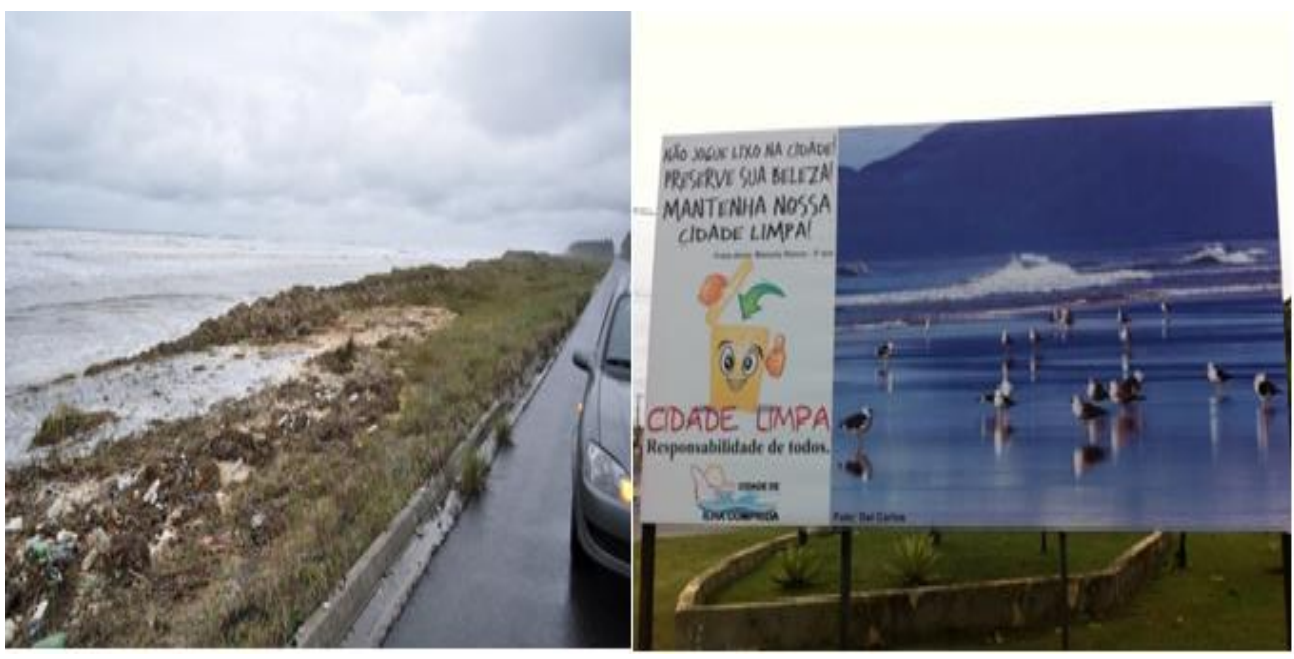

Foto 6: Concentração de resíduos sólidos na faixa litorânea devido à ressaca do mar (esquerda) e a campanha da prefeitura no Projeto Cidade Limpa (direita).

Fonte: Diogo F. Rodrigues (2013).

Photo 6: Concentration of solid waste along the coast due to the undertow (left) and the campaign of the city hall in the Clean City Project ( right).

Source: Diogo F. Rodrigues (2013). 


\section{A beleza da paisagem}

Mesmo que a transformação venha ocorrendo na llha Comprida devido à urbanização e desenvolvimento, ela continua demonstrando uma infinidade de belezas naturais na fauna, flora e suas interações ecológicas presente no bioma associado à vegetação de dunas (Foto 7), restinga, mata atlântica e mangue, sendo capaz de proporcionar atividades de ecoturismo como observações de espécies de aves migratórias e permanente, trilhas e mergulho que proporcionam prazer, conforto e paz (Fotos 8 e 9).

A opinião dos moradores entrou em consenso, como reforça o entrevistado D-6: “(...) porque a cidade que nós nascemos não pode escolher, mas sim a cidade que vivemos. Nasci em São Paulo por falta de opção, eu escolhi a llha Comprida para viver. Não mudaria nunca".

Com o modelo de turismo sol e praia, resulta no acúmulo de frequentadores nas regiões litorâneas mais próximas das regiões metropolitanas, a procura da Ilha Comprida vem aumentando a cada ano, mas ações de ecoturismo são poucos exploradas, concentrando quase toda a atividade turística na praia, como relatado pelo entrevistado D-6:

"Acho que teria mais coisas que poderíamos fazer. Como passeios ecológicos, explorar mais as dunas com responsabilidade, lógico, porque dá medo colocar o turismo na mão de qualquer pessoa e simplesmente devastar 0 ambiente. Eu acho que o turismo deveria ser mais explorado com profissionais. Preparar o povo, tanto os profissionais, como orientar os turistas. Precisa ser mais fiscalizado" (D-6, funcionário público, ens. sup.).

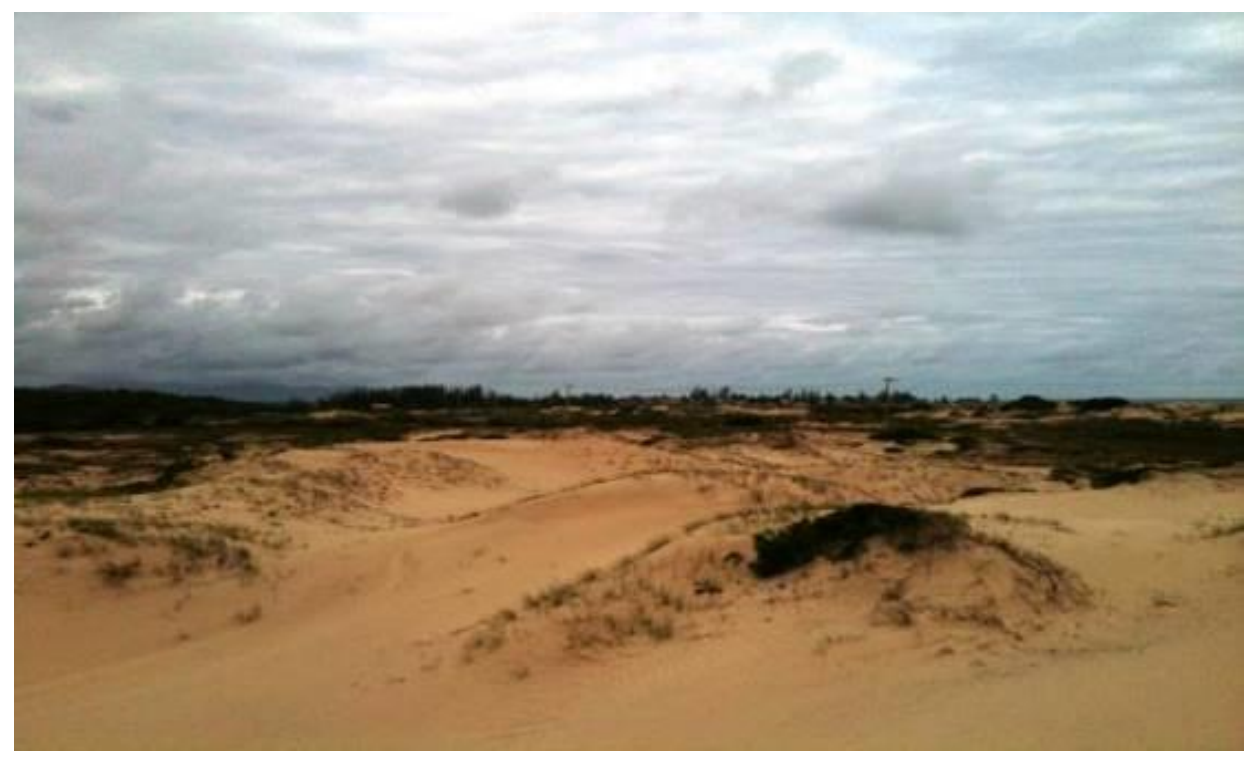

Foto 7: Dunas associada à vegetação rasteira. Fonte: Diogo Rodrigues (2013).

Photo 7: Dunes associated with undergrowth. Source: Diogo Rodrigues (2013). 
"O que mudou muito assim foi o pessoal ter conhecimento desses picos, como hoje a prefeitura faz passeios ecológicos, leva o pessoal para conhecer umas trilhas em Pedrinhas, então saiu uma parte da educação da população para não jogar lixo, evitar o máximo possível. Essa mudança veio com a população mesmo né, o pessoal começou a procurar mais aqui, devido às outras praias com muitos problemas como falta de água e superlotação" (D-1, comerciante, ensino médio).

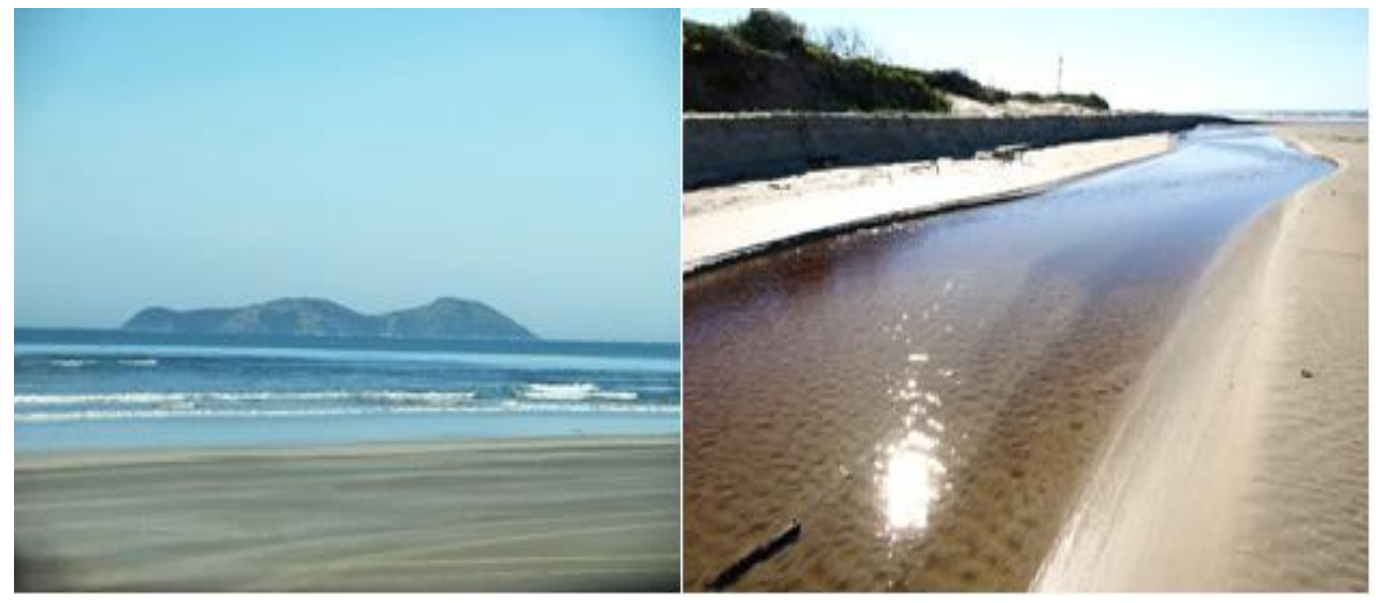

Foto 8: Beleza ao caminho do Boqueirão Sul.

Fonte: Diogo Rodrigues (2013); Izaias Carmacio Jr. (2012).

Photo 8: Beauty to the path of Boqueirão South.

Source: Diogo Rodrigues (2013); Izaias Carmacio Jr. (2012).

"Então o lugar que eu mais adoro na llha Comprida é o Boqueirão Sul. E sem contar o caminho até o Boqueirão sul, que é muito bonito, nas dunas de Juruauva" (D-6, funcionário público, ens. sup.).

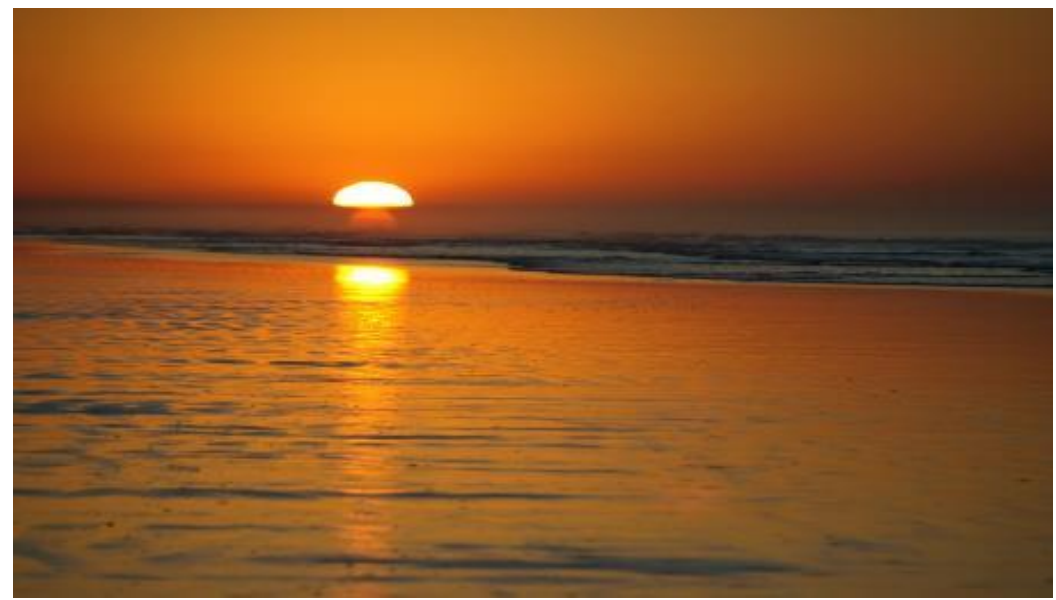

Foto 9: Amanhecer no horizonte da llha Comprida no Boqueirão Norte.

Fonte: Diogo F. Rodrigues (2012).

Photo 9: Dawn on the horizon of Long Island in Boqueirão Norte.

Source: Diogo F. Rodrigues (2012). 
Quando os entrevistados foram questionados sobre a possibilidade de residir em outro local, todos afirmaram que não abandonariam a Ilha, com exceção de alguns que eventualmente tenham motivos financeiros, mas pelo menos metade dos entrevistados afirmou que por motivo algum deixariam o "seu paraíso".

"Eu moro no paraíso, e nunca pensei em sair daqui, conheço quase todo o Brasil, mas nenhum lugar me chamou a atenção. Como disse antes, no meu bairro se não construir nenhuma casa mais, é melhor" (D-4, funcionário público, ensino médio).

\section{Considerações finais}

Ao ser convidado ao mundo de cada entrevistado, constatou o respeito e contemplação com o ambiente, nas entrevistas foram citadas muitas vezes a tranquilidade que faz parte da rotina dos moradores em época de baixa temporada, não havendo problemas com congestionamento, como no exemplo descrito no depoimento D-6:

“(...) na Ilha Comprida o que é legal no caminho de casa até o trabalho você cumprimenta todo mundo, você conhece todo mundo, sabe quem são, aqui tem paz e não tem trânsito".

Os moradores apontaram que o boqueirão Sul da Ilha Comprida tem um destaque na paisagem, justamente pelo atual estado de conservação influenciado pelo seu difícil acesso. Mencionam, inclusive, locais que somente eles tiveram a oportunidade de conhecer e guardam em suas memórias.

Com relação aos estudos sobre o imaginário e a relação com imagens, observa-se em Figueiredo (2010), que:

O estudo sobre o imaginário permite decifrar o sistema de imagens articuladas e a estrutura que se definem de modo a facilitar a compreensão do funcionamento e das dinâmicas pelas quais as imagens são incorporadas como conteúdo coletivo, implicando em visualizações, representações sociais, resistências, pré-conceitos, que podem, inclusive, comprometer a visão correta de um determinado conjunto de símbolos.

Observou-se que os moradores relacionaram a construção da ponte em 2001 como responsável pela ampliação da atividade turística e urbanização, trazendo benefícios e dinamização para a economia do município, por outro lado, trouxe problemas associados que antes não aconteciam, como delitos, interferências na paisagem natural e falta de segurança, uma vez que não há fiscalização eficiente. Em decorrência disso, ocorre também um aumento no acúmulo de resíduos sólidos. 
Nas imagens coletadas observou-se o aumento da mancha urbana com construções de vias de acesso, crescimento nos locais comerciais, alteração da fauna local, aterramento de áreas de manguezais, supressão da vegetação nativa e das dunas, impermeabilização do solo com construções e vias de acesso, locais com grandes concentrações de segundas residências, terraplanagem das dunas para as construções civis e o acúmulo de resíduos sólidos. Problemas com a qualidade da água, condições de vida, contaminação ambiental.

O Balneário Ponta da Praia é o local de maior destaque na percepção dos entrevistados, justamente por ser mais visível a alteração da paisagem, devido ao avanço do nível do mar. Resultando na perda gradativa de residências ano a ano. O turista, ao visitar o local onde foram realizadas as fotografias, não imaginará que neste local havia urbanização, porque atualmente é um local inundado, existindo no máximo alguns escombros, como marcas desse processo.

O município está enfrentando ameaças de novas destruições na avenida principal por conta da força marítima. As imagens relataram o processo de transformação na paisagem da llha Comprida que ocorreu até o ano de 2013, mas a pesquisa deduz que ainda haverá mais transformações no município se não for realizado uma intervenção para tentar controlar, ou até mesmo transferir os moradores que atualmente estão com suas residências próximas do mar, pois o que pode se observar é que o processo de transformação indica que seu processo de transformação não está concluído.

Ressalta-se, ainda, a necessidade de se provocar discussões e subsidiar ações de educação ambiental e ecoturismo, visando a melhoria da qualidade de vida e a conservação da paisagem natural nessa região do litoral Sul de São Paulo.

\section{Referências bibliográficas}

AMORIM FILHO, O.B. Os estudos da percepção como a última fronteira da gestão ambiental. Simpósio Situação Ambiental e Qualidade de Vida na Região Metropolitana de Belo Horizonte e Minas Gerais, 2, 1992, Belo Horizonte. Anais... Belo Horizonte, ABGE, 16-20, 1992. Disponível em http://sigcursos.tripod.com/percepcao ultima fronteira.pdf. Acesso em 04 out. 2013.

ARAUJO, G.K.T.M. Percepção ambiental, memória e transformação da paisagem: estudo de caso no sítio Tangará e bairros da região oeste de Santo André (SP). Trabalho de Conclusão de Curso (Bacharel em Ciências Biológicas) - Faculdade de Filosofia, Ciências e Letras, Centro Universitário Fundação Santo André, Santo André, 2006.

BEU, S.E. Análise socioambiental do complexo estuarino-lagunar de CananéiaIguape e llha Comprida (SP): subsídios para o planejamento ambiental da região. 2008. 133f. Dissertação (Mestrado em Ciência Ambiental) - Programa Interdisciplinar de Ciência Ambiental, Universidade de São Paulo, São Paulo, 2008.

COSTA-PINTO, A.B.; SORRENTINO, M. Trabalhos coletivos e educação ambiental para a participação: uma parceria com moradores de Pedrinhas, Ilha Comprida/SP. Revista Eletrônica do Mestrado em Educação Ambiental, v. 8, p. 21-34, jan./jun. 2002. 
DOMICIANO, C.S.; OLIVEIRA, I.J. Cartografia dos impactos ambientais no Parque Nacional da Chapada dos Veadeiros. Mercator, Fortaleza, v. 11, n. 25, p. 179-199, mai./ago. 2012

FIGUEIREDO, L.A V. Cavernas como paisagens racionais e simbólicas: imaginário coletivo, narrativas visuais e representações da paisagem e das práticas espeleológicas. 2010, 466f. Tese (Doutorado em Ciências, área de Geografia Física) - Faculdade de Filosofia, Letras e Ciências Humanas, universidade de São Paulo, São Paulo, 2010.

NOBRE, I.M. A fotografia como narrativa visual. Dissertação (Mestrado) Universidade Federal do Rio Grande do Norte. Natal, 2003.

NOBRE, I.M. Revelando os modos de vida da Ponta do Tubarão. Tese (Doutorado em Ciências Sociais) - Universidade Federal do Rio Grande do Norte. Natal, 2005.

NOBRE, I.M. A fotografia como narrativa visual: sinopse de dissertação. Rev. Inter-Legere. Natal, n. 5, p. 66-82, jul./dez. 2009.

NOBRE, I. M. Informação fotográfica, cultura e sociedade. Discursos Fotográficos. Londrina, v. 7, n. 10, p. 107-126, jan./jun. 2011.

TRAVASSOS, L. E. P. A fotografia como instrumento de auxilio no ensino da geografia. Revista de Biologia e Ciencias da Terra, ano/vol. 1, n. 02. Universidade Estadual da Paraíba. Campina Grande, 2001.

TUAN, Y.-F. Topofilia: um estudo da percepção, atitudes e valores do meio ambiente. São Paulo: Difel, 1980.

Izaias Carmacio Junior: Centro Universitário Fundação Santo André, Santo André, SP, Brasil.

E-mail: izaias-carmacio@hotmail.com

Link para o currículo Lattes: http://lattes.cnpq.br/1567144704499344

Diogo Fernando Rodrigues: Centro Universitário Fundação Santo André, Santo André, SP, Brasil.

E-mail: dii_morison@hotmail.com

Link para o currículo Lattes: http://lattes.cnpq.br/0955071404750441

Luiz Afonso Vaz de Figueiredo: Centro Universitário Fundação Santo André, Santo André, SP, Brasil.

E-mail: lafonso@fsa.br

Link para o currículo Lattes: http://lattes.cnpq.br/5253650313975776

Data de submissão: 26 de fevereiro de 2015

Data de recebimento de correções: 29 de outubro de 2015

Data do aceite: 29 de outubro de 2015

Avaliado anonimamente 